\title{
Student Perceptions of Inverted Classroom Benefits in a First-Year Engineer- ing Course
}

\section{Dr. Krista M. Kecskemety, Ohio State University}

Krista Kecskemety is a lecturer in the Engineering Education Innovation Center at The Ohio State University. Krista received her B.S. in Aerospace Engineering at The Ohio State University in 2006 and received her M.S. from Ohio State in 2007. In 2012, Krista completed her Ph.D. in Aerospace Engineering at Ohio State. Her engineering education research interests include investigating first-year engineering student experiences, faculty experiences, and the connection between the two.

Brooke Morin, Ohio State University 


\section{Student Perceptions of Inverted Classroom Benefits in a First-Year Engineering Course}

\section{Introduction}

The inverted classroom model has increased in popularity both in high school and university settings. This approach, sometimes referred to as a flipped classroom, "flips" the activities that are traditionally performed "out-of-class" with those traditionally performed "in-class". One advantage of this classroom approach is that the instructional staff can be used more effectively during learning activities rather than just providing lecture content. Online educational resources growing in popularity and the prevalence of technology in the daily lives of the students have eased and encouraged this transition to the inverted classroom.

As the inverted classroom model increased in popularity, many of its benefits have been discussed in the literature. ${ }^{1,2}$ Some of these include: making effective use of class time, making good use of technology, accommodating various learning styles, ${ }^{2,3}$ helping students become selflearners, ${ }^{2}$ fostering life-long learning skills, ${ }^{3}$ providing collaborative learning, ${ }^{3}$ personalizing learning, ${ }^{4}$ and increasing class time engagement. ${ }^{4}$

With these benefits in mind and due to contact time limitations and the desire for more active learning, the honors first-year engineering program at The Ohio State University elected to implement the inverted, or flipped, classroom model. ${ }^{5}$ Through this model, the instructors hoped to dedicate their contact time with students to addressing conceptual problems and facilitating inclass activities, rather than lecturing about factual material. Further, by holding students accountable for their pre-class preparation, the environment would foster the skills necessary for lifelong learning. First-year engineering courses have a unique position in implementing the inverted classroom approach because students have typically not had previous post-secondary experiences, and thus have fewer expectations for the post-secondary classroom. These limited previous experiences may help ease the transition to the inverted classroom.

Student perceptions of the inverted classroom have been investigated in various studies. Mason et al. ${ }^{2}$ found favorable results with the inverted classroom in a senior-level control systems course. By the end of the term the students rated the inverted classroom course as better than courses taught in a traditional format. Zappe et al. ${ }^{6}$ found that in an architectural engineering course $74 \%$ of students thought the flipped classroom was helpful in understanding the concepts. Despite this benefit, a majority (95\%) of the students indicated that they thought the flipped classroom approach in that course should only be used $50 \%$ of the time or less. Only $8 \%$ of the students, however, said the approach should rarely be implemented.

However, some papers have noted some of the criticisms or misunderstandings that students have of the inverted classrooms. Talbert, ${ }^{7}$ teaching a freshman MATLAB course, noted that students can feel that they are not being taught with the inverted classroom because they equate lecturing with teaching.

While previous research has investigated student perceptions of the inverted classroom, ${ }^{2,4}$ this paper seeks to address the following research questions that are focused on students' perceived 
benefits in a first-year engineering course: In what ways do students perceive that they benefit from the inverted classroom approach? Additionally, which classroom approach do students prefer and is there a connection to their perceived benefits?

\section{Methods}

\section{Course Description}

The fall semester course used in this study focused primarily on computer-aided problem solving using Excel, MATLAB, and $\mathrm{C} / \mathrm{C}++$. Academic integrity, engineering ethics, data analysis, team building, and the engineering design process were also covered. There was a laboratory component to the course, which included exercises from a variety of engineering disciplines. The inverted classroom model was applied to each course component. The theoretical framework for the inverted classroom approach is based on Bloom's taxonomy. Each instructional day was divided into two parts: preparation and application. The preparation component, completed before class, used lower-level Bloom's taxonomy skills of remembering and understanding. ${ }^{8}$ The preparation involved pre-class learning activities such as videos, reading assignments, and tutorials. Student completion of the preparation activity was evaluated either through an online quiz or through a short assignment submitted at the beginning of class. The application component began in the normal class period and included a short presentation, in-class activities, and assignments, often requiring students to use higher-level Bloom's taxonomy skills, such as application, analysis, and evaluation. The students were evaluated in the course based on the grade breakdown shown in Table 1 .

Table 1: First year engineering grade breakdown for the first semester course.

\begin{tabular}{|l|l|}
\hline \multicolumn{1}{|c|}{ Grade Category } & \% of Grade \\
\hline Preparation Assignments & $10 \%$ \\
\hline Application Assignments & $20 \%$ \\
\hline Laboratory Assignments & $21 \%$ \\
\hline Journals & $3 \%$ \\
\hline Design Project & $5 \%$ \\
\hline Extra Weekly Assignments & BONUS 3\% \\
\hline Quizzes & $6 \%$ \\
\hline Midterm Exams & $20 \%$ \\
\hline Final Exam & $15 \%$ \\
\hline
\end{tabular}

Thirteen sections of the course were offered in fall 2013, each containing 32-36 students. The classroom was arranged to encourage collaboration with students in groups of 4 with a desktop computer at each seat. Each course section had one instructor and two undergraduate teaching assistants.

\section{Survey Description}

To examine student perceptions, two surveys were administered to the students. Approximately 350 students participated in the study. The first survey was given at the end of the first week of the term. As Mason et al. ${ }^{2}$ found that inverted classroom perceptions were developed before the 
$4^{\text {th }}$ week of the term, it was important to administer this first survey as early as possible. Similar questions were then given to the students at the end of the semester as part of the final course survey. Students were asked which classroom approach they preferred: traditional (Trad), inverted classroom (IC), or a combination of partially traditional and partially inverted (PI). Additionally, the survey asked them to rank their opinion of the benefits of the inverted classroom on a 5-point Likert scale, from strongly disagree to strongly agree. The pre-test asked the students if they had experienced in the inverted classroom prior to Autumn 2013. The posttest survey then asked the students if they had experienced the inverted classroom in other courses during Autumn 2013. These questions were asked to give an idea of the prevalence of the inverted classroom and to suggest outside influences to their perceptions.

Since a majority of the questions asked in the survey required students knowing what the inverted classroom approach was, the following definition was provided in the survey:

"The inverted classroom model is based on the initial learning and exposure to a concept occurring outside of the classroom, before the students experience the material in-class. This outside of the classroom exposure can include reading, videos, tutorials or other learning devices or activities. The in-class time is then used to reinforce this knowledge through interactive learning activities, assignments, and projects. The amount of time spent by the instructor "lecturing" or "presenting" in the classroom setting is minimized (not the primary classroom activity) and is only used to help reinforce material, not deliver new content."

Note, this definition was intentionally written in a broad manner as definitions of the inverted classroom approach vary in the associated literature. ${ }^{9}$

\section{Results and Discussion}

\section{Student Instructional Approach Preferences}

The first item examined was the students' preferred classroom approach and how this changed from the pre-test to the post-test. The percentages for each classroom approach preference are shown in Table 2. Both before and after the semester, the partially inverted classroom approach received a majority of the responses. The inverted classroom approach remained relatively unchanged between the pre-test and post-test and the traditional lecture-based classroom approach increased by $5.3 \%$ from the pre-test to the post-test.

Table 2: Classroom approach preferences for the pre-test $(\mathrm{N}=351)$ and post-test $(\mathrm{N}=348)$. Results are given as the percent of total students included in each survey.

\begin{tabular}{|l|l|l|}
\hline & Pre-test & Post-test \\
\hline $\begin{array}{l}\text { Traditional lecture-based } \\
\text { classroom }\end{array}$ & $9.48 \%$ & $14.81 \%$ \\
\hline $\begin{array}{l}\text { Partially traditional and } \\
\text { partially inverted classroom }\end{array}$ & $75.57 \%$ & $71.51 \%$ \\
\hline Inverted classroom & $14.94 \%$ & $13.39 \%$ \\
\hline
\end{tabular}

While the overall averages remained similar between the pre-test and the post-test, it was important to also examine how individual students changed from the pre-test to the post-test. 


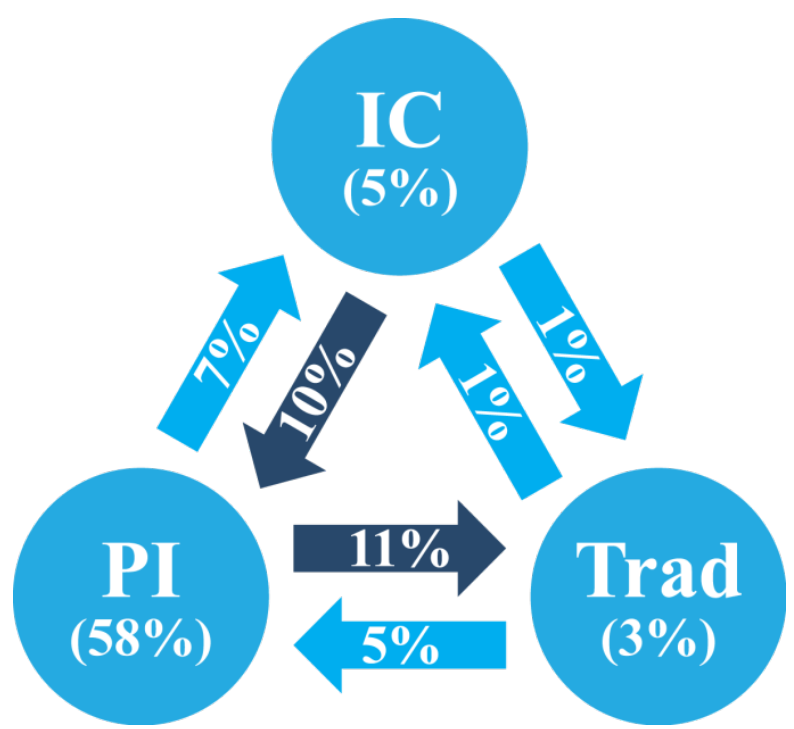

Figure 1: Student classroom approach preference changes from the pre-test to the post-test $(\mathrm{N}=348)$. The percentages in the circles are the percent of all students who preferred the same category both before and after the semester. The percentages in the arrows indicate the percent of all students who moved from one preference to another. Dark arrows indicate the largest changes. Trad - traditional, IC - inverted classroom, PI - combination of partially traditional and partially inverted.

As Figure 1 shows, the two categories that saw the largest changes from the pre-test to the posttest were from the partially inverted classroom approach to the traditional classroom approach (11\%) and from the inverted classroom approach to the partially inverted approach (10\%). Both of these movements suggest dissatisfaction with the inverted classroom approach for these populations.

\section{Exposure to IC in other Courses}

The prevalence of the inverted classroom was demonstrated in both the pre-test and post-test survey. In the pre-test, students were asked if they had experienced the inverted classroom approach prior to Autumn 2013. Because most of the students who participated in the study were first-year students, the fact that $41 \%$ of the students indicated they had seen the approach before suggests that the inverted classroom approach has become fairly common in K-12 education. Those students who had experienced the inverted classroom in previous classes had slightly more favorable opinions of the inverted classroom than their counterparts. This is shown in Table 3. The movement of the two groups from the pre-test to the post-test is very similar. In both cases the students reported decreased preference in the inverted classroom and increased preference in the traditional lecture-based classroom. 
Table 3: Students who indicated they had experienced the inverted classroom approach prior to Autumn 2013. The results for the pre and post-test are given as the percent of total students in each category (Yes or No).

\begin{tabular}{|l|l|c|c|c|}
\hline & \multicolumn{2}{|c|}{ Yes-41.09\% } & \multicolumn{2}{c|}{ No - 58.91\% } \\
\hline & Pre-test & Post-test & Pre-test & Post-test \\
\hline $\begin{array}{l}\text { Traditional lecture-based } \\
\text { classroom }\end{array}$ & $9.79 \%$ & $13.29 \%$ & $9.27 \%$ & $14.63 \%$ \\
\hline $\begin{array}{l}\text { Partially traditional and } \\
\text { partially inverted classroom }\end{array}$ & $73.43 \%$ & $72.73 \%$ & $77.07 \%$ & $68.78 \%$ \\
\hline Inverted classroom & $16.78 \%$ & $12.59 \%$ & $13.66 \%$ & $8.78 \%$ \\
\hline
\end{tabular}

In the post-test, students were asked if they had experienced the inverted classroom approach in any additional courses during Autumn 2013. 66\% indicated that the inverted classroom appeared in additional courses. This is not surprising since the physics and chemistry courses associated with this first-year engineering program used some inverted classroom methods. It is interesting that the students who did not indicate they had additional courses with the inverted classroom approach had an increased preference for the inverted classroom approach compared to the other population.

This, with the results above, warrants further investigation into what about the other courses did and did not produce favorable opinions about the inverted classroom. In the end-of-term survey, the students had an opportunity to comment with an open ended response and a few indicated statements like: "I thought the inverted classroom style worked well for ENGR1281H, but was difficult for a class like Physics", or "I feel the way this course was taught was very effective. It was the correct use of a flipped classroom, whereas other classes like chemistry do not use it correctly." Further investigation into why students feel this way could prove beneficial in improving the inverted classroom model for all subjects.

Table 4: Students who indicated they had experienced the inverted classroom approach in additional courses during Autumn 2013.

\begin{tabular}{|l|l|l|}
\hline & Yes $-66.38 \%$ & No $-33.33 \%$ \\
\hline $\begin{array}{l}\text { Traditional lecture-based } \\
\text { classroom }\end{array}$ & $16.31 \%$ & Post-test \\
\hline $\begin{array}{l}\text { Partially traditional and } \\
\text { partially inverted classroom }\end{array}$ & $72.96 \%$ & $69.23 \%$ \\
\hline Inverted classroom & $10.73 \%$ & $18.80 \%$ \\
\hline
\end{tabular}

\section{Student Perceived Benefits}

Students were asked to assess their perceived benefits of the inverted classroom through 15 Likert questions with the responses ranging from strongly disagree to strongly agree which are included in Figure 2 and Figure 3. Note that questions 2,4,10 and 14 were presented and answered in a negative way, however, the answers were inverted when presented in Figure 2 and Figure 3. The stacked bar charts in Figure 2 shows the comparison of responses from the pre-test to the post-test. The results in Figure 3 only have the post-test but are for the populations of 
students which indicated a preference for the traditional lecture-based approach and those that preferred the inverted classroom approach.

All areas of perceived benefits received a high number of agree or strongly agree responses, indicating that most students found the inverted classroom model to have benefits. From the pretest to the post-test the number of students that agreed or strongly agreed increased for questions Q8 (accommodates learning style) and Q14 (peer learning). This suggests that their experience in Autumn 2013 inverted classrooms helped demonstrate slight benefits in accommodating learning styles and helping them learn from their peers. One student who noted that the inverted classroom approach did not work for him/her stated: "I learn better by lectures and instructions, and I am not a very good self-learner, but I don’t mind the approach for this class, as it helped me develop these skills.” The largest decreases in students who agreed or strongly agreed from the pre-test to the post-test came in Q3 (focus on difficult topics) and Q15 (life-long learning skills). This may suggest room for improvement on the implementation of the inverted classroom if it is not allowing the instructors to focus on confusing topics. Also, since building life-long learning skills is a benefit that was hoped to be gained by the inverted classroom in this engineering course, this is an area that should be investigated further. Overall Q7-Q10 had the lowest numbers of students who agreed and strongly agreed in both the pre and post-tests. These questions focused on the benefits of the inverted classroom on personalizing learning. It is surprising that more students do not see this benefit however, approximately $50 \%$ or more do see this as a benefit of the inverted classroom.

It is not surprising that Figure 3 demonstrates that the students who prefer the inverted classroom approach recognize benefits in the inverted classroom at a much higher percentage than those that prefer a traditional lecture-based classroom. Q7-Q9 had the widest margin on those that agree that the inverted classroom provides these benefits. These questions again dealt with personalizing learning. It is reasonable that students who do not prefer the inverted classroom would also not think it personalized learning to them since their preference would be for a lecture-based classroom. The one category that had the closest agreement between the two populations was Q14, which was about learning from peers. One student noted, "I learned a lot from working on applications in class and discussing them with my peers.” 


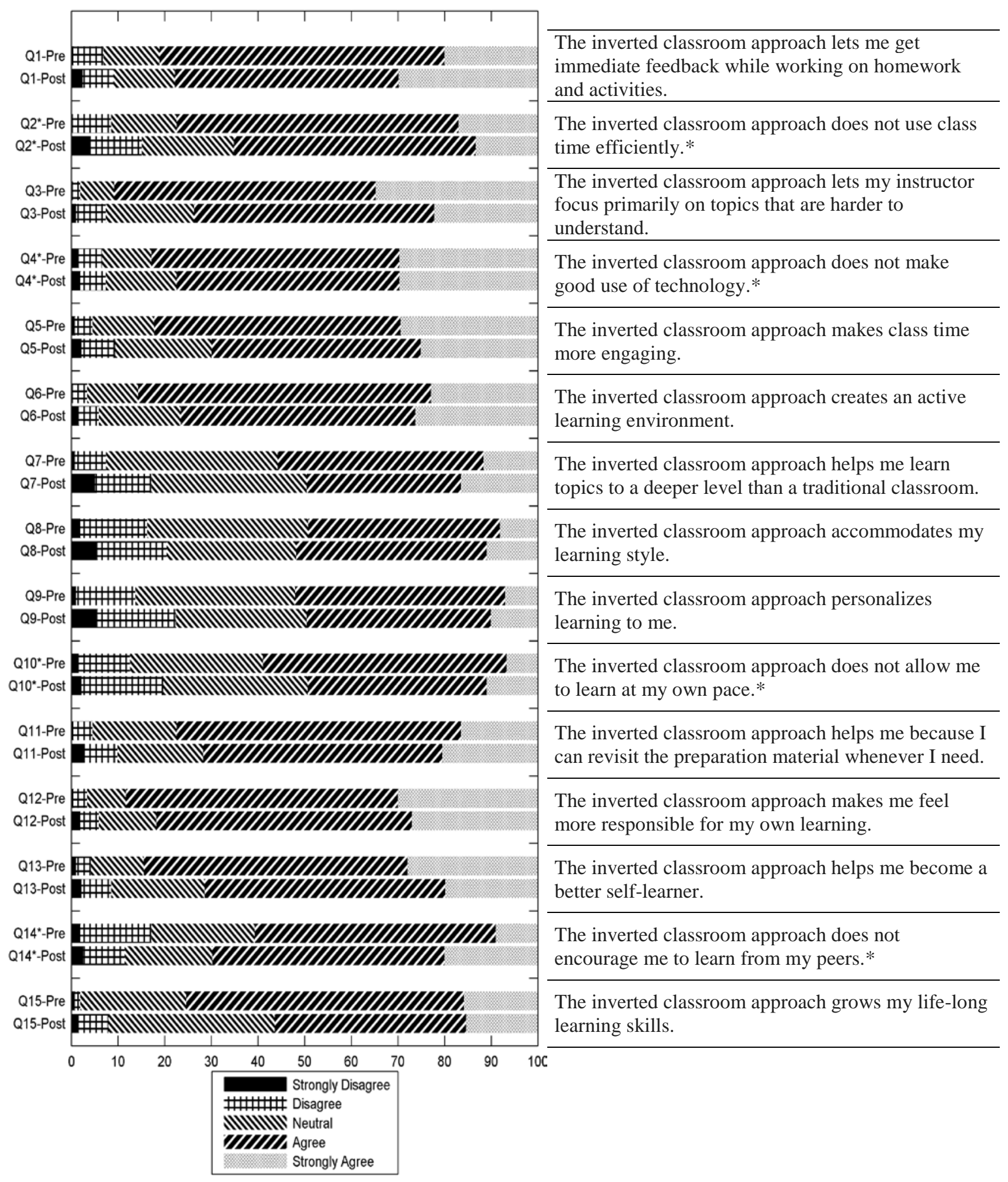

Figure 2: Perceived benefits of the inverted classroom pre-test and post-test survey results. Those questions asked in the negative (indicated by *) are shown with inverted responses in the graph, as if they were asked as positives. 


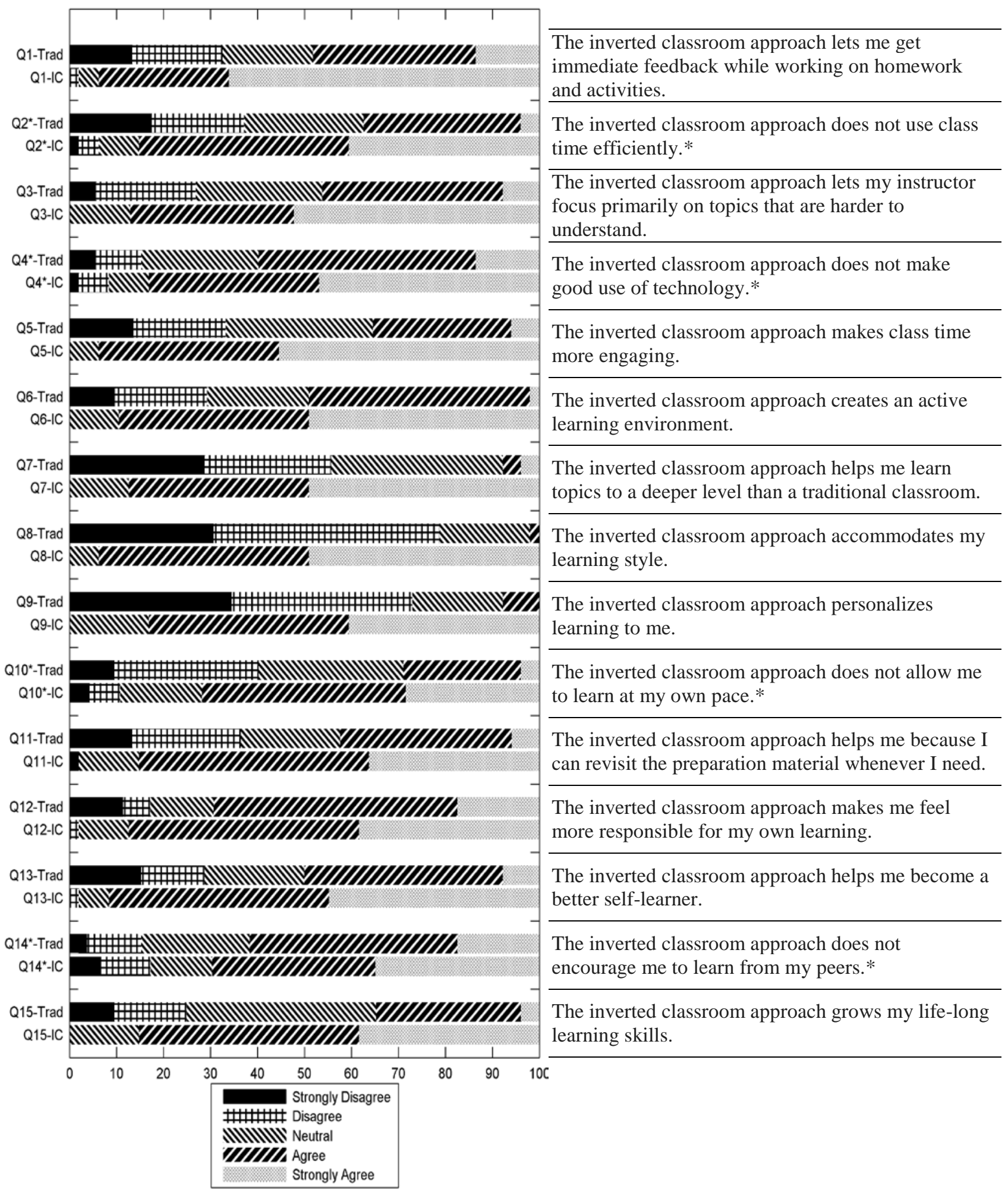

Figure 3: Perceived benefits of the inverted classroom approach post-test survey results organized by classroom approach preference. Those questions asked in the negative (indicated by *) are shown with inverted responses in the graph, as if they were asked as positives. 


\section{Preferred Classroom Approach and Relationship to Final Course Grades}

Lastly, the relationship between the preferred classroom approach and final course grade was examined. Using the student preference from the post-test, the students who preferred the traditional lecture-based classroom had a final course grade average of $87.36 \%$, the students with the preference of the inverted classroom approach had a final course grade average of $88.11 \%$ and the students who preferred a mixture of the two had an average course grade of $89.41 \%$. A histogram showing the grade distributions of the three preference populations is shown in Figure 4. Using the Wilcoxon rank-sum test, the grade distribution differences could not be considered statistically significant (Trad-IC $\mathrm{p}=0.2405$, Trad-PI $\mathrm{p}=0.6104$, IC-PI $\mathrm{p}=0.2986$ ).

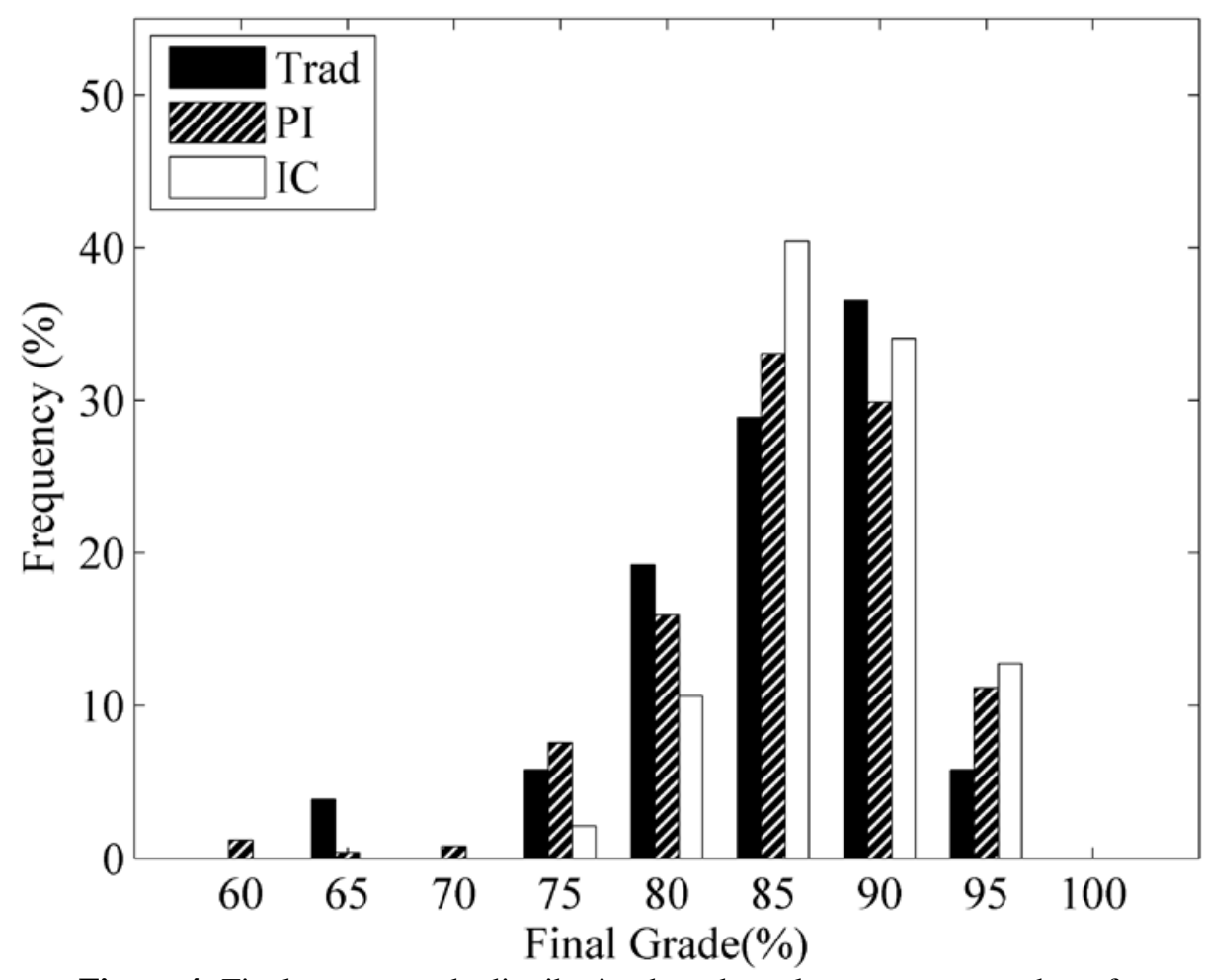

Figure 4: Final course grade distribution based on classroom approach preference

When examining each grade component the only category that demonstrated statistically significant differences in these three populations was a bonus 3\% that could be earned through weekly extra credit programming assignments. These assignments were optional, but students were encouraged to complete them. As shown in Table 5, the students who preferred the inverted classroom approach earned over $15 \%$ more extra credit than those that preferred the traditional lecture-based approach and over $10 \%$ higher than those that preferred a partially inverted approach. This result is particularly interesting because the extra credit is the closest element of the course to a traditional homework assignment, as the students complete it independently outside of the classroom. However, this may result from those students who prefer the inverted approach being more comfortable with learning independently. 
Table 5: Extra credit percent of points earned out of the 3\% maximum based on classroom approach preference. A significant difference is represented by a p-value $<0.05$, indicated by $*$, or a p-value $<0.01$, indicated by $* *$.

\begin{tabular}{|c|c|c|c|}
\hline & Trad & IC & PI \\
\hline Average & $38.99 \%$ & $55.63 \%$ & $44.17 \%$ \\
\hline p-value & \multicolumn{2}{|c|}{$0.0098^{* *}$} & \\
\hline p-value & & \multicolumn{2}{|c|}{$0.0337 *$} \\
\hline
\end{tabular}

\section{Conclusions}

While most of the students in this engineering course see benefits to the inverted classroom model, most of them still prefer to have some traditional classroom elements present. This preference increased as students gained exposure to the inverted classroom. The effect was even more apparent when students were enrolled in other courses using an inverted approach. However, it appears that student preference did not have a significant effect on course performance, so that even those students who would prefer a traditional model still performed well in the class.

There are a few areas of this study that suggest further investigation may be beneficial. The first is determining why the students do not prefer a fully inverted classroom. Students mentioned needing to adapt to the approach so it is possible that additional training in the beginning of the semester might ease this transition. Future surveys, student focus groups and interviews could try to determine the reasons for the students' preference. The open ended responses collected this term will provide a valuable starting point for developing this survey. Some of the criticisms of the inverted classroom approach included:

- "I felt lost at times trying to learn the material by myself first."

- "I thought that it took a lot of pressure and responsibility off the teacher and put it on the student instead."

- "professors are the best at explaining the material and addressing questions right when they arise. When reading a book, the material is usually more technical and there is no interaction.”

The survey did not ask which of these three classroom approaches the students thought was used in the engineering class. The inverted classroom model was specifically stated to them at the beginning of the term as the approach used in this course. While it was assumed that the students understood the class was structured with an inverted classroom model, one student wrote in the final course evaluation: "The partially inverted approach is extremely beneficial and I couldn't have done the class without it.” Thus, it is not clear whether students considered the course in question to be a fully inverted course or a partially inverted course, which may have affected the results. For instance, if a student perceived the course to be partially inverted and had a positive experience, they would skew preferences toward the partially inverted category. Future surveys should ask students which level of inversion is present in the course in which they are currently enrolled.

Additionally, it would be beneficial to investigate faculty perceptions and their link to student perceptions. The faculty teaching various sections of this course had different levels of involvement in creating the course content and that could potentially play a role in student 
perceptions. Additionally, while the course content and structure were the same, faculty had varying lecture lengths, order of classroom events/activities and possible variations in the focus on preparation work.

Approximately two-thirds of the students indicated that they were exposed to the inverted classroom in other courses during the semester this study was completed. However, it is unclear to what extent those other courses inverted the classroom and what inversion strategies were used. Further exploration of the effects of additional inverted classroom exposure in these classrooms might provide further knowledge about the shift in student preference away from full inversion.

While this study was conducted only on the population of students currently taking this course with the inverted classroom approach, previous students took similar courses with a slightly more traditional model. Future studies could survey these students to see their opinions of the course and the different teaching approaches used. Similar survey data could be collected again in a few years with the current student population that experienced the inverted classroom to make a comparison.

Finally, this study focused on an honors first-year engineering course. The entire first year engineering program at The Ohio State University uses the inverted classroom approach. The study should be expanded to the entire first year engineering program to determine if there are any differences due to the different populations, different course content, different contact time available, and different class sizes.

\section{Acknowledgements}

The authors would like to acknowledge the Fundamentals of Engineering for Honors instructional staff for their assistance in developing materials used in this course and administering the survey to collect data. Also, the authors would like to thank Dr. Deb Grzybowski for her valuable input and guidance in the planning stages of this study.

\section{References}

1. J.F. Strayer. "How learning in an inverted classroom influences cooperation, innovation and task orientation", Learning Environments Research, vol. 15, 171-193, 2012.

2. G. Mason, T.R. Shuman, and K.E. Cook. "Inverting (Flipping) Classrooms - Advantages and Challenges," in Proceedings of the Annual Conference of the American Society of Engineering Education, 2013.

3. L. Bland. "Applying Flip/Inverted Classroom Model in Electrical Engineering to Establish Life-Long Learning," in Proceedings of the Annual Conference of the American Society of Engineering Education, 2006.

4. M.W. Redekopp and G. Ragusa. "Evaluating Flipped Classroom Strategies and Tools for Computer Engineering,” in Proceedings of the Annual Conference of the American Society of Engineering Education, 2013.

5. M.J. Lage, G.J. Platt, and M. Treglia. "Inverting the Classroom: A Gateway to Creating an Inclusive Learning Environment," The Journal of Economic Education, vol. 31, no. 1, Winter 2000. 
6. S. Zappe, R. Lieicht, J. Messner, T. Litzinger, and H. Woo Lee. “ 'Flipping' the classroom to explore active learning in a large undergraduate course.” in Proceedings of the Annual Conference of the American Society for Engineering Education, 2009.

7. R. Talbert. "Learning MATLAB in the Inverted Classroom." in Proceedings of the Annual Conference of the American Society of Engineering Education, 2012.

8. L.W. Anderson, et al. A Taxonomy for Learning, Teaching, and Assessing. Addison Wesley Longman, Inc., Illinois, 2001.

9. J.L. Bishop and M.A. Verleger, "The Flipped Classroom: A Survey of the Research," in Proceedings of the Annual Conference of the American Society of Engineering Education, 2013. 